\title{
As Ciências Sociais e Humanas em Saúde na Associação Brasileira de Pós-graduação em Saúde Coletiva
}

\author{
| ${ }^{1}$ Ana Maria Canesqui |
}

Resumo: Abordam-se a trajetória, estrutura, organização e implementação das atividades da Comissão de Ciências Sociais e Humanas em Saúde da Associação Brasileira de Pósgraduação em Saúde Coletiva, no período 1981 a 2006, articulando-a aos contextos das diretorias que lhes forneceram maior apoio, destacando as diferentes gestôes da associação e da comissão. Documentos, matérias divulgadas nos boletins da associação, relatórios de gestão e atas da comissão, pronunciamentos de ex-coordenadores e bibliografia específica sobre o assunto foram consultados, assim como dados informalmente obtidos de alguns ex-coordenadores ou membros da comissão. Conclui-se que, das dificuldades iniciais de fazer interlocução com a área da Saúde Coletiva, as ciências sociais se legitimaram, ampliaram seus objetos e disciplinas, firmando sua identidade, que requer novos espaços. A comissão organizou-se, estabeleceu normas informais, definiu e redefiniu o sistema de representação e seu formato, destacando: a promoção de eventos científicos, os diagnósticos e planos para solucionar os problemas da subárea, resposta às atribuições que lhe foram dadas pela associação e às iniciativas de seus intelectuais de delimitar o papel das ciências sociais e humanas na Saúde Coletiva, organizando seus profissionais e intervenções.

\author{
${ }^{1}$ Professora adjunta, Doutora e \\ Livre-docente, colaboradora do \\ Departamento de Medicina \\ Preventiva e Social, área de \\ Ciências Sociais Aplicadas à \\ Medicina. Faculdade de \\ Ciências Médicas da \\ Universidade Estadual de \\ Campinas e ex-coordenadora \\ da Comissão de Ciências \\ Sociais e Humanas em Saúde \\ da Associação Brasileira de \\ Pós-graduação em Saúde \\ Coletiva. \\ Endereço eletrônico: \\ anacanesqui@uol.com.br.
}




\section{Introdução}

Reconstitui-se a trajetória da organização e implementação das atividades da Comissão de Ciências Sociais e Humanas em Saúde (CCSHS), inserida na estrutura organizacional da Associação Brasileira de Pós-graduação em Saúde Coletiva (Abrasco), ao lado de sua diretoria, conselho de associados institucionais e das demais comissóes e grupos de trabalho. Este texto complementa esforços anteriores, como o de Belisário (2002), que pioneiramente reconstituiu a história da Abrasco, usando documentos e depoimentos de suas lideranças, como atores articulados em torno da instituição e alguns textos de autores da coletânea organizada por Lima e Santana (2006), comemorando os 25 anos da associação.

Ao percorrer a trajetória da CCSHS no período 1981 a 2006, articulam-se a organização e implementação das atividades aos contextos das estratégias das diferentes diretorias que lhe oferecem maior incentivo, selecionadas previamente a partir da leitura de bibliografia e documentos. $\mathrm{O}$ texto transcende o mero registro das informações, sendo que a organização da comissão responde simultaneamente às atribuiçôes fixadas pela Abrasco e ao consenso e iniciativas dos cientistas sociais sobre a necessidade de marcar a identidade da subárea de conhecimento, de desenvolvê-la e aprimorá-la, uma vez constituinte e integrante da Saúde Coletiva, onde se entrecruzam distintos saberes e práticas. As atividades implementadas pelas diferentes gestôes da comissão retratam as iniciativas e apoios de seus integrantes.

Consultaram-se documentos específicos da comissão, como os relatórios, atas de reuniōes (quando disponíveis), comunicações das gestōes divulgados nos boletins da Abrasco, além de informações de ex-coordenadores ou integrantes da comissão que prestaram informaçôes complementares à autora, por via eletrônica ou oralmente ${ }^{1}$.

\section{Formulações das atribuições da comissão}

Comissões e grupos de trabalho são "braços" da diretoria da associação, segundo um dos entrevistados de Belisário (2002), cujas finalidades, apontadas no início da estruturação da associação, eram duas: estabelecer políticas de ensino e pesquisa nas suas respectivas áreas e desenvolver programação editorial (BELISÁRIO, 2002).

Em 1986 acrescentaram-lhes as atribuições de divulgar a análise das políticas públicas e dos problemas das áreas; colaborar na organização dos eventos; desenvolver 
atividades de cooperação técnica; identificar recursos humanos, materiais e financeiros para viabilizar as iniciativas propostas, definidas ao longo de seus trabalhos (BELISÁRIO, 2002). Tanto é que se concedeu maior autonomia decisória e financeira às comissões, ao lado de centralizá-las no eixo das proposições da política pública de saúde, no diagnóstico e intervenções sobre os problemas identificados no ensino, pesquisa, embora reconhecidas as especificidades das distintas disciplinas da Saúde Coletiva.

Quando foi revisto o estatuto da associação, as comissões redefiniram-se como grupos assessores do processo de Saúde Coletiva e suportes para as reflexões e tomada de decisōes da diretoria (BELISÁRIO, 2002), tornando-se orgânicas e compromissadas com o projeto da Saúde Coletiva, unificando as distintas áreas de conhecimento em torno da interdisciplinaridade e das atribuições e ligações delas com as estratégias das decisões da diretoria, interlocução e respaldo dos interessados.

Tomam-se estes enunciados, não apenas como referências formais, mas de concepções formuladas sobre as atribuições das comissões, pelas diferentes gestôes da Abrasco, embora na implementação e funcionamento das atividades da associação e das próprias comissões pudessem aparecer outras concepções não-formalizadas sobre suas atribuiçôes, cuja análise completa demandaria acionar mais amplamente as memórias do conjunto de atores ex-integrantes da CCSHS, o que foge às possibilidades imediatas.

\section{Breve perfil da Abrasco}

Desde sua criação, em 1979, e durante a década de 1980, a Abrasco implantouse como associação articuladora dos interesses do campo da Saúde Coletiva no país; reuniu as instituições formadoras de recursos humanos e as diferentes correntes de pensamento político-ideológicas, científicas e partidárias presentes no campo. Primeiramente, implementaram-se avaliações e orientaçôes do ensino da Saúde Coletiva e de suas diferentes áreas na graduação e pós-graduação sensu lato, que perderam prioridade posteriormente, exceto em áreas específicas. Avaliaram-se os cursos de pós-graduação stricto sensu e a política científica e tecnológica, desde a década de 1990, embora se verifiquem esforços anteriores de diagnosticar e orientar a política de recursos humanos neste nível na década de 1980 (BELISÁRIO, 2002; MINAYO, 2006). 
A Abrasco participou ativamente da formulação da política de saúde, como ator político, marcando algumas diretorias a face política da associação (BELISÁRIO, 2002) na década de 1980, no contexto de redemocratização do país; da Assembléia Nacional Constituinte, da formação do Sistema Único de Saúde (SUS) e elaboração da Lei Orgânica da Saúde.

Fortaleceram-se, simultaneamente, as áreas específicas, organizadas em comissões próprias: Epidemiologia, Ciências Sociais e Planejamento, ao lado dos diferentes Grupos de Trabalho, contribuindo para demarcar suas identidades, cujos eventos próprios e os gerais da Abrasco - fóruns científicos, de reflexão e debate da política de saúde -, divulgaram as produções científicas, fornecendo visibilidade à associação, no espaço político-institucional.

$\mathrm{Na}$ década de 1990, debateram-se as conquistas constitucionais e a implementação do SUS, esforçando-se para garantir as bases legais obtidas e a implantação do modelo de gestão do SUS (universal, descentralizado e participativo). Isto resultou no comprometimento de articular a política de saúde às diferentes esferas executivas de governo-federal, estadual e municipal - para garantir o processo de descentralização, o funcionamento dos conselhos de saúde, juntamente com as conferências nacionais de saúde e dos congressos da Abrasco (FONSECA, 2006, p. 29- 30).

Ao lado do reforço à política de formação de recursos humanos na pósgraduação stricto sensu, as intervenções junto à Coordenação de Aperfeiçoamento de Pessoal de Nível Superior (Capes), Conselho Nacional de Pesquisa (CNPq) e aos setores de Ciência e Tecnologia do Ministério da Saúde geraram instâncias decisórias próprias à Saúde Coletiva, como o comitê do CNPq e a representação da área de Saúde Coletiva na Capes, responsável pelo julgamento e avaliação dos cursos de pós-graduação. Formou-se o Fórum de Coordenadores dos Cursos de Pós-Graduação em Saúde Coletiva, no interior da Abrasco. O desenvolvimento da política editorial gerou novos canais à divulgação da produção científica, como as revistas Ciência \& Saúde Coletiva e de Epidemiologia.

A associação, nos primeiros seis anos do século XXI, resgatou estrategicamente a intervenção na política de saúde, centrando-se na implementação do SUS e da própria Reforma Sanitária, em um novo contexto político e econômico. Após os progressos obtidos, persistem problemas, impondo obstáculos à maior eqüidade. Deu-se a maior flexibilidade e reforma do Estado, embora a condução da política 
de saúde e a implementação do SUS ainda não efetivassem inteiramente o direito universal à saúde dos cidadãos, proporcionando-lhes acesso e promoção da cidadania.

Simultaneamente, naquele período esforçou-se na articulação internacional da associação, com outras latino-americanas, mundiais e canadense de saúde pública, ou nas áreas específicas (Ciências Sociais; Epidemiologia; Gestão e Planejamento; Saúde Reprodutiva e Gênero; Saúde e Trabalho e outras) facilitando tanto as alianças e o intercâmbio acadêmico de algumas instituiçôes do campo, de seus respectivos cursos de pós-graduação ou interesses de seus intelectuais, quanto à realização de eventos científicos conjuntos. Não é novidade a internacionalização da associação, à medida que a Abrasco, nas palavras de Noronha (BELISÁRIO, 2006, p. 58) "nasceu com uma visão internacionalista [...] uma vez fundada no final dos anos 70, o foi sob a égide de uma reforma democrática internacional da utopia de um mundo de irmãos".

A Abrasco continua contribuindo na consolidação dos cursos de pós-graduação e formulação dos conteúdos de ciência e tecnologia adotados na área (MINAYO, 2006), refletidos ainda no amadurecimento das ciências sociais e humanas em saúde, na formulação de ajustes e de novos parâmetros de julgamento de sua produção acadêmica, persistindo a meta atual de promover sua identidade nas instituições de ciência e tecnologia, sempre a partir da multidisciplinaridade. Questionam-se, pertinentemente, o relativo abandono de outros níveis de ensino, focos iniciais da associação, com possíveis reflexos na perda da renovação de quadros futuros para a área (CAMPOS, 2000, p. 3).

\section{As diretorias e os incentivos às ciências sociais e humanas em saúde}

\section{A década de 1980}

Os esforços da primeira diretoria deram-se em torno da organização e institucionalização da Abrasco, sob a presidência de Frederico Simões Barbosa e demais componentes, como Guilherme Rodrigues da Silva, Ernani Braga e José da Silva Guedes, no período 1979 a 1981.

Na segunda diretoria (1981-1983), estavam Benedictus Philadelpho de Siqueira (presidente), José da Silva Guedes, Jairnilson Paim, Ernani Braga e Paulo Buss. Dentre as atividades, destacaram-se: 1) a manutenção das residências de Medicina Preventiva e Social e a formação de especialistas em Saúde Pública; 2) constituição 
do campo da Saúde Coletiva e das diferentes disciplinas que o ancoram; 3) produção editorial (Série Estudos de Saúde Coletiva e Boletim); 4) organização do I Congresso Nacional da Abrasco e II Congresso Paulista de Saúde Pública, São Paulo, ocorrido em 17 a 21 de abril de 1983; 5) implantação dos grupos de trabalho sobre as residências médicas em Medicina Preventiva e Social, a avaliação dos cursos de Saúde Pública e do ensino de Medicina Preventiva e Social.

Quanto às ciências sociais, deu-se a I Reunião Nacional sobre Ensino, Pesquisa de Ciências Sociais na área da Saúde Coletiva, em São Paulo, no mês de julho de 1982, promovida por Abrasco/Departamento de Medicina Social da Faculdade de Ciências Médicas da Santa Casa de São Paulo (ARCOVERDE, 2006). No foco das discussões sobre a formação de especialistas para a Saúde Coletiva, estavam as ciências sociais nos cursos de residência em Medicina Preventiva e Social e especialização em Saúde Pública, cujos problemas identificados foram: 1) dificuldades de inserção dos docentes de ciências sociais, devido às posturas críticas em relação aos saberes e práticas de Saúde Coletiva; 2) cargas horárias variadas dos cursos oferecidos; 3) coexistência de formaçóes diferentes dos docentes: uns formados em ciências sociais (sociologia, economia e ciências políticas), enquanto outros formados em medicina, com mestrado em Saúde Coletiva; 4) os assuntos selecionados para o ensino das ciências sociais foram: os determinantes sociais do processo saúde/doença; condições de saúde da população, relações entre saúde e sociedade, organização social da prática médica, orientando-se pela corrente de Medicina Social. Havia forte tensão entre a aplicação do conhecimento e o ensino calcado nas teorias das ciências sociais.

As recomendações foram as seguintes: 1) promoção de cursos para atualização dos docentes; 2) criação de um programa editorial permanente; 3) divulgação ampla e sistemática das oportunidades formais de capacitação no Brasil e exterior, através dos Boletins da Associação e do Catálogo de Pós-Graduação; 4) ampliação do programa de bolsas da Capes e CNPq e outras instituições; 5) ampliação dos mecanismos de intercâmbio, apoio, coordenação e assessoria técnica entre os programas no biênio 1982/1983; 6) incorporação das ciências sociais na pesquisa em saúde (ABRASCO, 1983).

Formaram-se as comissões editoriais da Abrasco, incluindo a de Ciências Sociais, em função da necessidade de produzir textos e bibliografia para a Saúde Coletiva. Sem dispor dos resultados dos trabalhos dessas comissões e de suas políticas 
editoriais, divulgaram-se os Estudos de Saúde Coletiva, no período de 1982 até o final da década de 1980, contendo artigos, diagnósticos do ensino, programas de pesquisa (Peses/Finep), relatórios e recomendações das reuniões e seminários sobre o ensino das diferentes áreas da Saúde Coletiva, nos seus respectivos níveis.

Eleita a terceira diretoria no primeiro Congresso Nacional da Abrasco para o triênio 1983-1985, Hésio A. Cordeiro esteve na presidência com os demais componentes: José da Rocha Carvalheiro, Francisco Eduardo Campos, Tânia Celeste Matos Nunes e Paulo Buss. As diretrizes formuladas foram: 1) passagem da teoria à prática, tornando-se a Abrasco ator político na formulação da política de saúde; 2) fortalecimento do movimento sanitário no contexto da redemocratização do país; 3) reforço ao ensino e formação de recursos humanos; 4) construção do campo da Saúde Coletiva; 5) articulação com as agências de fomento; 6) criação da comissão de política de saúde na etapa preparatória da VIII Conferência Nacional de Saúde.

Realizou-se o curso de atualização dos docentes e pesquisadores da área de CSS (Salvador-Bahia, de 16 a 27 de maio de 1983), propondo-se "articular os diferentes centros de pós-graduação em Saúde Coletiva no país, estimulando-se a discussão e formulação, pelo conjunto dos docentes pertencentes aos programas e práticas de ensino e investigação na área de Ciências Sociais em Saúde" (ABRASCO, 1984, p. 145). Diagnosticou-se a situação do ensino das ciências sociais nos cursos de pósgraduação lato sensu, propondo-se a organização e aperfeiçoamento da residência e especialização em Saúde Pública. (ABRASCO, 1984).

Promovido por Abrasco/CNPq e Capes, o curso teve como organizadores Sebastiāo Loureiro (UFBA), Carmem Fontes Teixeira (UFBA) e Tânia Celeste Matos Nunes, com 50\% dos participantes oriundos das regiōes Norte e Nordeste e os demais da Região Sudeste (São Paulo, Rio de Janeiro e Minas Gerais), procedendo do corpo docente de várias instituiçôes: Universidade de São Paulo, Faculdade de Saúde Pública, Faculdade de Medicina da Santa Casa, Escola Nacional de Saúde Pública, Universidade do Estado do Rio de Janeiro, Universidade Federal da Bahia, Fundação Getúlio Vargas e Universidade Estadual de Campinas. Contou com a assessoria da Organização Pan-Americana da Saúde, através de Juan César Garcia, e da Universidade Autônoma do México, através de Asa Cristina Laurell.

Os conteúdos desse curso deixaram nítida a tendência de articular teorias sociológicas ao exame dos determinantes do processo saúde/doença, sob o 
materialismo histórico; diagnosticar e analisar as condições de saúde da população; desenvolver a Epidemiologia Social e analisar a organização social da prática médica e de setores específicos, como a saúde do trabalhador e os movimentos sociais em saúde. Foram conteúdos do curso: 1) fundamentos teóricos das ciências sociais, correntes de pensamento, sua incorporação às práticas de pesquisa em Saúde Coletiva e métodos e técnicas de investigação; 2) evolução histórica das condições de saúde das populaçôes; 3) desenvolvimento das Ciências Sociais no estudo da saúde; da determinação do processo saúde/doença e no enfoque teórico da análise do social em saúde; 4) técnicas de investigação na epidemiologia social; 5) pesquisas em políticas e práticas de saúde; 6) política de saúde ocupacional e movimentos sociais e saúde.

Esboçou-se uma proposta para uniformizar os propósitos, conteúdos e metodologia do ensino das ciências sociais que conduzisse o aluno a tomar consciência do contexto em que se insere e dos limites do saber e das práticas médicas tradicionais; capacitá-lo a elaborar uma descrição distinta da realidade, incorporando a visão crítica do social e não apenas ideológica, e produzir conhecimentos sobre a conjuntura de saúde. A metodologia de ensino deveria partir de textos de medicina social e não das ciências sociais disciplinares. Os debates sobre a proposta recusaram uniformizar aquele ensino em torno do projeto da corrente de medicina social, em função da diversidade das ciências sociais e de sua desejada articulação com as demais disciplinas (Planejamento em Saúde e Epidemiologia) na redefinição das práticas de saúde coletiva (ABRASCO, 1984).

Em janeiro de 1986, criou-se a Comissão de Ciências Sociais (CCS), junto com as comissões de outras subáreas da Saúde Coletiva e da Comissão de Políticas de Saúde (ARCOVERDE, 2006), permanecendo a primeira a cargo de Everardo Duarte Nunes e Amélia Cohn. A força da conjuntura política e o forte empenho da associação no processo de Reforma Sanitária priorizaram a implementação das atividades da Comissão de Política de Saúde, que funcionou autonomamente às demais ciências sociais, atuando fortemente na formulação e vocalização da política de saúde, defendida pela associação e pela militância do movimento sanitário, tendo permanecido, posteriormente, apartada das primeiras.

\section{A década de 1990}

No período 1989 a 1991, José da Silva Guedes presidiu a associação ao lado de Nilson do Rosário Costa, Carmem Fontes Teixeira, Alina Maria Almeida de Souza 
e Péricles Silveira da Costa, componentes da diretoria que implementaram as seguintes atividades: 1) ampliação da representação política da Abrasco no Conselho Nacional de Saúde; 2) organização, identidade e atuação da área de Epidemiologia, realizando seu primeiro congresso específico; 3) estímulo à organização das demais comissões, elaboração de seus respectivos planos e atuação da comissão de política na análise da Saúde no Governo Collor; 4) desenvolvimento e aprimoramento da pós-graduação.

A “dura sobrevivência da Abrasco" foi a expressão utilizada por Belisário (2002) para caracterizar esta diretoria, que enfrentou uma conjuntura marcada por contradições em torno dos sucessos obtidos nos amparos legais para a implementação do SUS (Lei Orgânica da Saúde e instalação do Conselho Nacional de Saúde) e da forte redução do financiamento das políticas públicas (GOLDBAUM; BARRADAS, 2006, p. 89).

Iniciativas de agregar os cientistas sociais da área da saúde e realizar encontros nacionais ocorreram em 1990, pelo Grupo de Trabalho Saúde e Sociedade, que pretendia atuar junto à Associação de Pós-Graduação em Ciências Sociais (ANPOCS), o que não teve êxito. O GT fez o I Encontro de Cientistas Sociais do Rio de Janeiro no Instituto de Filosofia e Ciências Sociais da Universidade do Estado do Rio de Janeiro, sob a coordenação de Madel T. Luz (UERJ) e Maria Tereza Ewbank (ENSP), assim como outro encontro durante a $43^{\text {a }}$ Reuniāo da SBPC (LUZ; EWBANK, s/d).

As professoras elaboraram o documento "Quem é quem em ciências sociais e saúde”, identificando 77 profissionais da área, demonstrando sua alocação nãoexclusiva no Rio de Janeiro. Esse número saltou para 158 no Catálogo de Cientistas Sociais em Saúde (ABRASCO, 1995), organizado após o I Encontro de Ciências Sociais em Saúde, realizado em 1993 em Belo Horizonte².

A idéia de traçar um programa de trabalho para as ciências sociais gerou um outro grupo de trabalho, reunido no mês de dezembro de 1990 (ABRASCO, 1990), com as presenças de Madel T. Luz (IMS), Amélia Cohn (USP/CEDEC), Nísia Trindade Lima (COC/FIOCRUZ), Regina Célia Bodstein (ENSP), Rubens Adorno (FSP-USP), Fabíola Zione (FSP-USP), Everardo Duarte Nunes (UNICAMP) e Nilson do Rosário Costa (ENSP), além de Péricles da Silveira, da secretaria executiva da associação, que colocaram na pauta de suas discussões a seguinte questão: o que se constitui a área de ciências sociais em saúde? 
As respostas demarcaram suas características: as diversidades profissional, teórica e temática; distinção entre militância política e a contribuição das ciências sociais à Saúde Coletiva, cujo "chamado à prática" e à reinvenção social ocuparam a década de 1970; a necessidade de dar visibilidade à produção científica; a superação do saber militante e vigilância epistemológica. Impuseram-se os seguintes desafios: a releitura do corpo teórico das ciências sociais; a maior qualificação dos cientistas sociais; a captação de novos profissionais; a maior articulação das ciências sociais com as disciplinas da Saúde Coletiva; a produção de metodologias e práticas de pesquisa; o estabelecimento de uma agenda de pesquisas sobre a cidadania, direitos, desigualdades sociais e não apenas sobre a reforma setorial (ABRASCO, 1990).

A sexta diretoria (1991-1993) teve Arlindo Fábio Gómez de Souza na presidência e, como demais integrantes: Maria Cristina Lodi Guedes, José da Rocha Carvalheiro, Júlio S. Muller Neto e Péricles da Silveira, cujas atividades recuperaram a representação da Abrasco no Conselho Nacional de Saúde. Organizaram-se outros grupos de trabalho (informação em saúde, comunicação em saúde e saúde do trabalhador); realizou-se o III Congresso de Saúde Coletiva, assim como o II Congresso Brasileiro de Epidemiologia e IV Congresso de Saúde Coletiva, além da I Reunião Nacional dos Conselheiros de Saúde; planejou-se, ainda, avaliar os cursos de pós-graduação stricto sensu.

A conjuntura financeira adversa para a associação não impediu a realização do I Encontro Brasileiro de Ciências Sociais em Saúde, realizado de 28/9 a 1\%/10/ 1993 em Belo Horizonte, promovido por Abrasco e Departamento de Medicina Preventiva da Universidade Federal de Minas Gerais. O encontro propôs congregar os cientistas sociais em fórum próprio, reconhecendo a ausência de reunião como lacuna que impedia a discussão e o equacionamento dos problemas, a identidade profissional, o aperfeiçoamento dos métodos de pesquisa e ensino e o estabelecimento de interface com outros grupos da Saúde Coletiva, assim como o debate sobre a crise da saúde no país (ABRASCO/UFMG, 1993).

As palavras de Arlindo Fábio Gomes no discurso de abertura daquele evento retrataram as primeiras dificuldades de introduzir as ciências sociais no campo da saúde, nos seguintes termos:

[...] nas discussões intermináveis, na busca da interdisciplinaridade os planejadores eram muito claros ao nos dizer que o planejamento não tinha nada a ver com a Sociologia e muito menos entendiam o que a Sociologia Política poderia dar de 
contribuição [...]. Os epidemiólogos simplesmente desconheciam a sua mãe, a Antropologia, e nós costumávamos dizer de que o problema de reconhecimento da mãe é da ordem de cada um [...]. A Sociologia mostrava a determinação social das enfermidades, o sistema econômico, a organização econômica do país, mas as questóes da saúde eram vistas absolutamente isoladas do social [...]. Cecília Donangelo [...] nos mostra a possibilidade de utilização das categorias sociais na sua forma mais pura, digamos assim [...]. Outros procuravam de alguma maneira a aplicação desse conhecimento na área médica [...]. Domingos Gandra fez algo extremamente importante, ademais de sua contribuição às Ciências Sociais, que foi fazer a pesquisa sobre a pesquisa. (GOMES, 1993, p. 25).

Compuseram a comissão organizadora desse encontro: Ana Maria Canesqui (UNICAMP), Madel T. Luz (IMS), Maria Cristina Lody Mendonça (UFMG), Rosa Maria Quadros Nehmy (UFMG) e Maria Teresa O. Ewbank (ENSP); e ainda Péricles da Silveira e Mariana Aparecida Lelis Adão, da secretaria executiva da associação. O objetivo do evento, que contou com 200 inscritos, foi: "congregar os profissionais das ciências sociais que atuam na área da saúde, sendo urgente a sua aglutinação em fórum próprio e adequado de expressão" (ABRASCO/UFMG, 1993).

A programação incluiu uma conferência magna; cinco oficinas sobre a interdisciplinaridade no ensino das ciências sociais, a contribuição dos cientistas sociais na construção do campo da saúde; comunicação social e saúde; saúde mental: a abordagem das ciências sociais; três painéis; duas mesas-redondas, tendo sido intencionalmente um evento mais restrito para aprofundar, nas oficinas, as reflexōes sobre as ciências sociais e seu papel na Saúde Coletiva ${ }^{3}$.

Debateram-se a seguir as ciências sociais em saúde numa oficina realizada em 1995, no Rio de Janeiro, organizada pela comissão, com os objetivos de mapear e deliberar a participação das ciências sociais no campo da saúde, para qualificar suas contribuiçôes; diagnosticar os problemas da área nas suas distintas dimensões (ensino, pesquisa e participação nos serviços de saúde e no campo do conhecimento). Quatro mesas-redondas constaram da programação das atividades, e dentre as conclusões estava o resgate do caráter heurístico das ciências sociais na pesquisa, o aprofundamento das reflexões sobre sua inserção na pesquisa e nas teorias e metodologias (ABRASCO, 1995, p. 5).

A divulgação dos textos daquela oficina e de outros, apresentados no I Encontro, compôs a coletânea (CANESQUI, 1995) contendo reflexōes sobre os dilemas e perspectivas teórico-metodológicas contemporâneas das ciências sociais - a "crise 
de paradigmas" - que as direcionam a adotar teorias de médio alcance e integrar as abordagens micro e macro, assim como dirigir o olhar para o sujeito e a singularidade, tão esquecidos pelo enfoque histórico-estrutural sob a égide do marxismo, antes dominante nas pesquisas em Saúde Coletiva. Refletiram-se, ainda sobre a interdisciplinaridade, os movimentos sociais e o ensino e formação dos recursos humanos nos serviços de saúde.

Sobre essa coletânea, Madel T. Luz escreveu: "os cientistas sociais desta coletânea são todos da área - antropólogos, historiadores, cientistas políticos, sociólogos (que predominam) -, decidiram dedicar suas vidas de pesquisadores e professores à questão da saúde, criando uns campos novos, ricos e nobres de teoria e investigação" (LUZ, 1995, s/p).

Integrantes da comissão provisória organizadora daquele encontro tornaramse, em 1994, membros da nova CCSS: Ana Maria Canesqui (coordenadora UNICAMP), Madel T. Luz (UERJ), Maria Cecília de Souza Minayo (ENSP), Nízia Trindade de Lima (COC-Fiocruz), Paulo César Alves (UFBA), Eduardo Stotz (ENSP) e Rosa Quadros Nehmy (UFMG). Recompôs-se esta comissão, com a saída de Maria Cecília de S. Minayo para presidir a Abrasco, incorporandose Mercês Somarriba (UFMG), substituindo Rosa Maria Quadros Nehmy e Regina Giffoni Marsiglia (Santa Casa - SP), permanecendo os demais membros até o mês de dezembro de 1996.

A diretoria seguinte (1994-1996) foi presidida por Maria Cecília de Souza Minayo, ao lado de Mariliza Berti de Azevedo Barros, Renato Peixoto Veras, Pedro Miguel dos Santos Neto, Péricles da Silveira e João Carlos Canos Mendes, ambos na secretaria executiva. Esta diretoria tanto atuou na face acadêmica, quanto na política da associação, reforçando os trabalhos das comissões e grupos de trabalho. Nas palavras de Goldbaum \& Barradas (2006, p. 94):

a necessidade de fortalecimento da pós-graduação em Saúde Coletiva respondia a dois tipos de problemas: de um lado, a já mencionada necessidade de produzir novos conhecimentos que embasassem a implementação do Sistema Único de Saúde, e de outro, o questionamento mais ou menos velado, do caráter científico do campo.

Dentre as realizações desta diretoria, destacaram-se inúmeras atividades, tais como o fortalecimento da pós-graduação em Saúde Coletiva, avaliando a área, e a organização dos seguintes eventos: I Conferência Nacional de Ciência e Tecnologia; III Congresso de Epidemiologia e X Conferência Nacional de Saúde. Obteve-se 
legitimidade da Saúde Coletiva no CNPq e Capes; instituiu-se o Fórum de Coordenadores dos Programas de Pós-Graduação em Saúde Coletiva; estimulouse a divulgação da produção científica da área, criando-se a Revista Ciência \& Saúde Coletiva e a Livraria da Abrasco. Reformularam-se os estatutos da associação, dando-se novos incentivos às comissões e grupos de trabalho; articulou-se a Plenária de Saúde junto com Centro Brasileiro de Estudos em Saúde e Fenam, tendo atuado a diretoria no Conselho Nacional de Secretários de Saúde e Conselho Nacional de Secretários Municipais de Saúde.

Realizou-se o I Congresso Brasileiro de Ciências Sociais em Saúde, de 7 a 10 de novembro de 1995, em Curitiba ${ }^{4}$, apoiado fortemente pela diretoria da associação e com empenho da própria CCS, da comissão científica e da local, esta última formada pelos integrantes da Secretaria de Estado da Saúde de Curitiba e de seu Núcleo de Estudos em Saúde Coletiva. Presidido por Ana Maria Canesqui, o congresso reuniu 500 inscritos, incluindo a programação: três conferências magnas; seis palestras; seis mesas-redondas; 11 cursos; 43 comunicações coordenadas; 231 pôsteres ${ }^{5}$.

No discurso de abertura daquele evento, Canesqui (1995, p. 2) reconheceu a ampliação das interlocuções das ciências sociais com os demais campos disciplinares da Saúde Coletiva, as dificuldades da geração de conhecimentos híbridos, as tensões existentes no campo e os compromissos com a construção do SUS. Nas suas palavras, "diante da desfavorável conjuntura pela qual passa o SUS, que se esfacela aos nossos olhos [...], juntamente com os cientistas sociais, profissionais de saúde aqui presentes não deixaremos fora da pauta de reflexões os vários temas que afligem o sistema de saúde”. Lembrou ainda que

se há pendências não resolvidas nas relaçôes interdisciplinares, talvez seja fértil e enriquecedor garantir o pluralismo, entre as ciências sociais, quando elas se debruçam sobre o objeto saúde, em sentido amplo [...], tratando-se de um pluralismo renovado e maduro, no qual a transposição das barreiras disciplinares não deve pôr em risco as suas identidades particulares (CANESQUI, 1995, p. 3)

Retomando-se a Carta de Curitiba, pronunciamento oficial daquele congresso, lê-se:

Cidade e Saúde, tema central do congresso, enseja reflexôes sobre a modernidade e sua possível superação, bem como a necessidade de garantir qualidade de vida para as populaçôes. O Congresso adota a concepção ampliada de saúde, definida 
na VIII Conferência Nacional de Saúde de 1988. [...] Reconhece ainda o quanto é importante a apropriação da saúde pelo cidadão, acentuando o valor da promoção dessa [...]. Julga que as políticas de saúde devem ser formuladas e implementadas de forma integrada a um conjunto de políticas sociais, obedecendo ao critério de qualidade [...] Observa o quanto a perda progressiva do espaço público que acompanha o processo de metropolização acarreta danos físicos, sociais e morais às populações e ao ambiente [...]. Avalia como socialmente importante e teoricamente relevante a integração entre as instituições de ensino, pesquisa, os serviços de saúde e a vida das populaçôes [...]. Reconhece com nitidez os vários desafios apresentados à sociedade brasileira neste final de século e de milênio: de um lado, a transição epidemiológica e sua descontinuidade, aliada ao quadro das profundas desigualdades sociais e regionais do país, de outro lado, afirma a necessidade de resguardar o Estado nacional, modificando-o e fortalecendo-o, no sentido de torná-lo apto a atender às necessidades de saúde dos cidadãos, apoiado na solidariedade social e superando a tradicional dicotomia "paternalismo versus mercado" (ABRASCO, 1995, p. 1).

Uma coletânea (CANESQUI, 1997) reuniu parte dos textos apresentados ao I Congresso e na Oficina, realizada no Rio de Janeiro em 1995, cujos conteúdos abordaram questões mais gerais da Saúde Coletiva e as diferentes definições deste campo; os rumos das ciências sociais em saúde no Brasil, reflexôes sobre o campo de conhecimento, a política de saúde; a inserção das ciências sociais no ensino e suas relações com os serviços de saúde e movimentos sociais, sendo estes o principal núcleo de questôes que instigavam os cientistas sociais naquele momento.

Sobre esta coletânea, que expressa a reflexão de vários cientistas sociais, disse Minayo (1997, s/p), presidenta da Abrasco, na ocasião:

esta obra, portanto, continua e aprofunda a múltipla responsabilidade das ciências sociais com o setor saúde, numa linha de diálogo com os temas de que ambos se ocupam. Busca assim contribuir ao mesmo tempo para a construção teóricometodológica desse campo intelectual e adequar-se aos problemas permanentes e emergentes que o mundo da vida lhe propõe como desafio.

Outra atividade implementada por aquela comissão foi o I Plano Diretor das Ciências Sociais em Saúde (ABRASCO, 1997), calcado nas discussões travadas em três oficinas preparatórias, que contaram com a ampla participação dos cientistas sociais das várias instituições e realizadas no Rio de Janeiro (1995), Campinas (1996) e em Águas de Lindóia (1997), durante o V Congresso Brasileiro de Saúde 
Coletiva, quando se concluiu o documento cujos conteúdos serão retomados posteriormente. Elaborou-se também, naquela gestão, o Catálogo dos Cientistas Sociais em Saúde (ABRASCO, 1997).

Durante as freqüentes reuniōes da comissão com membros da diretoria da Abrasco, pela primeira vez as discussões se encaminharam para integrar as ciências humanas às ciências sociais em saúde, sugerindo a mudança da denominação da comissão para Comissão de Ciências Sociais e Humanas em Saúde, à medida que não se tratava apenas de abordar, na Saúde Coletiva, o social, o econômico e o político, mas outras dimensões, como a ética, emocional, filosófica, histórica e antropológica (ABRASCO, 1994). Somente no início da década de 2000 reconheceu-se a maior amplitude da Saúde Coletiva e, no seu âmbito, das ciências sociais e humanas, alterando-se a denominação da comissão.

Recompôs-se novamente a CCSS (dezembro de 1996 a dezembro de 1997), com os seguintes integrantes: Ana Maria Canesqui (coordenadora-Unicamp), Paulo César Alves (UFBA), Madel T. Luz (UERJ), Regina G. Marsiglia (FM Santa Casa) e Mercês Somarriba (UFMG), acrescentando-se novos membros: Regina C. Bodstein (ENSP) e Cristina M. O Fonseca (COC-FIOCRUZ). Alterou-se novamente a comissão em dezembro de 1997, permanecendo na coordenação Paulo César Alves (UFBA), ao lado de Regina G. Marsiglia, Regina Bodstein e Cristina M. O. Fonseca, sugerindo-se novos integrantes, que foram mantidos até o término da gestão da diretoria da Abrasco.

A sétima diretoria (1997-1999) esteve sob a presidência Rita de Cássia Barradas Barata, ao lado de Eduardo Navarro Stotz, Everardo Duarte Nunes, Maria Elizabeth Diniz Barros, Mário Roberto Dal Poz, Oswaldo Yoshimi Tanaka e Péricles da Silveira, sendo João Carlos Canossa Mendes e Álvaro Hideyoshi Matida secretário executivo e secretário executivo-adjunto, respectivamente.

Esta diretoria se pautou nas seguintes diretrizes: defesa do direito à saúde e da produção científica e tecnológica, reforçando-se a representação da área de Saúde Coletiva na Capes e Ministério da Saúde. Vários eventos foram realizados: VI Congresso Brasileiro de Saúde Coletiva; IV Congresso de Epidemiologia; I Encontro Latino-americano em Saúde, Eqüidade e Gênero; IV Congresso de Epidemiologia, I Congresso Internacional Mulher, Trabalho e Saúde; II Conferência Brasileira de Ciência e Tecnologia. Criaram-se a Revista Brasileira de Epidemiologia, os cursos de especialização em Epidemiologia; a parceria internacional da Abrasco com a 
Associação Canadense de Saúde Pública, criando-se novos grupos de trabalho na Abrasco (GOLBAUM; BARRADAS, 2006).

Promoveu-se o II Congresso Brasileiro de Ciências Sociais em Saúde de 7 a 10 de dezembro 1999, em São Paulo, sob a presidência de Paulete Goldemberg, com o tema central “Ciências Sociais e Saúde: tendências, objetos, abordagens”, promovido por Abrasco e Departamento de Medicina Preventiva da Universidade Federal de São Paulo. Uma comissão local, uma comissão ampliada e a comissão científica encarregaram-se de organizá-lo. A comissão ampliada constituiu-se de 13 pessoas, entre membros da diretoria da Abrasco, cientistas sociais pertencentes às diferentes instituições e os integrantes da comissão de CSS (ABRASCO/UNIFESP, 2000).

Ao reconstituir a trajetória da institucionalização das ciências sociais no âmbito da Saúde Coletiva, as palavras de Goldenberg, contidas no discurso de abertura do congresso, justificaram a escolha do tema: "a área se expande demonstrando a necessidade de um balanço de seu desenvolvimento e da produção correspondente. Não é, portanto, sem motivo que o tema deste $2^{\circ}$ Congresso é Ciências Sociais e Saúde: objetos, tendências e abordagens". O evento contou com 578 inscritos ${ }^{6,7}$, incluindo-se no programa sete cursos; três conferências magnas; nove mesasredondas; 443 trabalhos expostos em comunicações coordenadas; 1.589 pôsteres e 10 oficinas temáticas e um perfil (ABRASCO/UNIFESP, 2000).

Editou-se a coletânea com textos apresentados no congresso, organizada por Goldenberg, Marsiglia e Gomes (2003), sobre a qual Amélia Cohn afirmou:

com esta coletânea, que mescla um contingente expressivo de cientistas sociais da área da saúde com outros cientistas sociais que não têm como característica em sua trajetória intelectual ter a saúde como objeto, creio que ganhamos todos, e que essa vitória não é corporativa, é uma vitória do campo da Saúde Coletiva. E certamente para isso também contribuiu a participação de pesquisadores e intelectuais com formação em outras áreas de conhecimento, porque é exatamente desse diálogo que o novo pode emergir de forma criativa, sempre e desde quando não renegue o clássico $(\mathrm{COHN}, 2003$, s/p).

Após este evento e no período de abril de 1999 a julho de 2002, deu-se um "mandato tampão" da comissão, coordenada por Paulete Goldenberg (UNIFESP), ao lado de Regina Bodstein (ENSP), Regina G. Marsiglia (FM. Santa Casa), Cristina M O Fonseca (COC-FIOCRUZ), Everardo Duarte Nunes (Unicamp), Eduardo Stotz (ENSP), Luiz Antônio de Castro Santos (UERJ), Nísia Trindade 
de Lima (COC-Fiocruz) e Mara Helena de A. Gomes (UNIFESP). Sugeriu-se a necessidade de ampliar a representação das instituiçõos, estados e disciplinas na comissão, reiterando-se a inclusão das ciências humanas à comissão, o que se efetivou logo a seguir na alteração da designação da comissão.

\section{Os anos 2000: "Um retorno ao momento político?"}

Esta pergunta de Belisário (2002) caracteriza a nova diretoria da gestão 20002003, presidida por José Carvalho de Noronha e composta por: Francisco Eduardo Campos, Jairnilson Paim, Márcia Furkim de Almeida, Paulo Marchiori Buss, Paulo Eduardo Mangeon Elias; e ainda Péricles Silveira da Costa e Álvaro Hideyoshi Matida (estes da secretaria executiva da associação), que se pronunciaram em defesa da saúde no Brasil, após tantos anos de instabilidade na implementação do Sistema Único de Saúde, alinhando-se com o Centro Brasileiro de Estudos em Saúde na elaboração da carta "Em defesa da saúde dos brasileiros". Mobilizaram-se a comunidade científica, os serviços e gestores da saúde em torno do VII Congresso de Saúde Coletiva, um grande evento, realizado no Rio de Janeiro em 2004.

As principais atividades desta diretoria foram: a reconstrução da agenda da pós-graduação, pesquisa e política de saúde; fornecimento de mais visibilidade política à associação (articulação com Conselho Nacional de Saúde, Conass e Conasems); o estabelecimento de parceria com outras associaçôes internacionais (World Federation of Public Health Association), dando continuidade ao trabalho junto a Capes e CNPq; participação na XII Conferência Nacional de Saúde "Atualizando a Agenda da Reforma Sanitária brasileira", criação de novos grupos temáticos (Saúde dos Povos Indígenas, Promoção da Saúde, Vigilância Sanitária e Saúde e Ambiente); I Conferência Nacional de Vigilância Sanitária; V Congresso de Epidemiologia; II Seminário Nacional de Saúde e Ambiente; I Simpósio Brasileiro de Vigilância Sanitária, assim como a indexação, na base Scielo, da Revista Ciência \& Saúde Coletiva (GOLDBAUM; BARRADAS, 2006).

A organização de eventos marcou as atividades da CCSHS nesse período, como nos demais, sendo que a promoção do próximo congresso da área de CSHS, previsto para 2004, foi prejudicada pelos obstáculos financeiros da associação e ocupação da agenda da diretoria com outros eventos significativos na conjuntura favorável à política de saúde. Programou-se, no seu lugar, o II Encontro de Ciências Sociais em Saúde, a realizar-se na fase pré-congresso do VII Congresso Brasileiro de Saúde 
Coletiva em Brasília, tendo como tema central "Saúde, Cidadania e Justiça". Elaborou-se também uma extensa pauta de assuntos para este encontro, tais como: racionalidades e práticas em medicina e saúde; estudos sociais da ciência e da técnica; gênero e saúde; avaliação de políticas e programas de promoção da saúde; subjetividade e cultura; comunicação e redes de informação; violência e saúde; construção social da saúde e doenças; instituições e políticas de saúde e bioética (LIMA, s/d), refletindo antigas e novas preocupações da subárea de conhecimento.

Outros eventos mobilizaram um número restrito de cientistas sociais no Seminário Ciências Sociais e Humanas em Saúde: Desafios da Saúde e da Vida, coordenado por Nísia Trindade de Lima. Este seminário foi promovido pela Fundação Oswaldo Cruz, no Rio de Janeiro, de 12 e 13 de dezembro 2002, pela Comissão de Ciências Sociais da Abrasco, Casa de Oswaldo Cruz/Instituto de Medicina Social e Escola Nacional de Saúde Pública. Apenas quatro mesasredondas compuseram o programa do evento, em torno dos seguintes assuntos: desafios contemporâneos das ciências sociais: a agenda da Saúde Coletiva e a contribuição das ciências sociais; Ciências sociais e saúde nos anos 90: balanço e perspectivas e uma oficina para discussão de assuntos e suas ementas para o próximo congresso da área (ABRASCO, 2003).

No folheto de divulgação do seminário, lêem-se as seguintes justificativas: "a crescente interferência do conhecimento biológico e biomédico na vida da sociedade. A redefinição de fronteiras entre as ciências biológicas e sociais; novas tecnologias e sua importância na sociabilidade; novas abordagens e teorias sobre a dimensão social do processo saúde e doença; cidadania e eqüidade”. O objetivo do evento foi refletir sobre a contribuição recente das ciências sociais para os estudos do campo da Saúde Coletiva, considerando a natureza interdisciplinar e a multiplicidade de objetos (ABRASCO, 2002). Desde julho de 2002, a CCSHS esteve sob a coordenação de Nísia Trindade de Lima (COC-Fiocruz), e os demais integrantes não nos foram informados.

A décima diretoria (2003-2006) foi presidida temporariamente por Moisés Goldbaum, que, pelo fato de ter assumido outras atribuiçôes, foi substituído pelo vice-presidente, Paulo Ernani Gadelha, em 2005. Os demais componentes da diretoria foram: Júlio S. Muller, Madel T. Luz, Rômulo Maciel Filho, Soraya Maria Vargas Côrtes, Álvaro Hideyoshi Matida e Mônia Mariani - os dois últimos na secretaria executiva da associação. Dentre as atividades, destacaram-se o VI 
Congresso Brasileiro de Epidemiologia; II Simpósio Brasileiro e Simpósio PanAmericano de Vigilância Sanitária; II Conferência Nacional de Ciência e Tecnologia; Conferência Luso-Francófona em Saúde (Montreal-Canadá); VII Congresso Brasileiro de Saúde Coletiva e XI Congresso Mundial de Saúde Pública; a proposta de criação de instância setorial de fomento à pesquisa; a comemoração dos 25 anos de criação da Abrasco (reunião na sede da OPAS em Brasília), sendo criado ainda o grupo de trabalho de Bioética.

Em 2003, convocou-se uma oficina que se propôs a atualizar o plano diretor da área e estabelecer as bases do Simpósio Nacional que, além de diagnosticar os problemas da área, discutiu novos arranjos da estrutura da $\mathrm{CCSH}$, que serão retomados posteriormente. Reconhecia uma das propostas a diversidade das formaçōes dos profissionais atuantes na área, o difuso crescimento das CSHS e a necessidade de qualificar a produção científica, assim como foi proposta a inclusão apenas dos portadores de formação específica na graduação e pós-graduação em ciências sociais (ABRASCO, 2003, p. 18-19). Verificam-se, neste sentido, resistências ao caráter "híbrido" dos profissionais da área de ciências sociais.

A Abrasco apoiou o VII Congresso Latino-Americano de Ciências Sociais em Saúde, realizado em Angra dos Reis, de 19 a 23 de outubro de 2003 e promovido pelo Fórum Mundial de Ciências Sociais e Medicina. Outros apoios foram obtidos do CNPq, Ministério da Saúde, Fundação Oswaldo Cruz e Instituto de Medicina Social da UERJ e outras instituições nacionais e internacionais, como a Organização Pan-Americana da Saúde, a Fundação Ford e International Development Research Canadien. O congresso enfatizou as contribuições das ciências sociais para a superação dos grandes desafios da Saúde Coletiva na região (MINAYO; COIMBRA, 2005). A iniciativa do Fórum Mundial de Ciências Sociais e Medicina, criado há 20 anos em torno da revista Social Science and Medicine, integrou cientistas sociais de vários países.

A tendência à internacionalização da Abrasco, presente na sua origem, intensificou-se a partir de 2000, como dito acima, através do estabelecimento de filiações ou da promoção de eventos científicos conjuntos com outras associações internacionais, dentre elas a World Federation of Public Health (WFPHA), Associação Latino-Americana e do Caribe de Educação em Saúde Pública (ALAESP), Associação Latino-Americana de Medicina Social (ALAMES), Associação Canadense de Saúde Pública (CPHA) e o Global Forum for Health Research, com 
algumas associações internacionais de Epidemiologia, além do permanente apoio da Organização Pan-Americana da Saúde, no desenvolvimento de algumas subáreas, desde a década de 1970.

Em maio de 2004, ocorreu o Simpósio Nacional sobre Ciências Sociais e Humanas em Saúde, realizado no Instituto de Medicina Social da Universidade do Estado do Rio de Janeiro, com um número restrito de participantes, objetivando "reconstruir e fortalecer a área de conhecimento na Abrasco e no país [sendo] também um momento estratégico para suscitar questões que nortearão o Congresso Nacional de Ciências Sociais e Humanas em Saúde, a ser realizado em maio de 2005" (ABRASCO, 2003, p. 3). Antecedeu este simpósio uma oficina de trabalho realizada no Rio de Janeiro, de 29 a 30 de julho de 2003, reiterando-se a diversidade de identidades e formações profissionais da subárea, sua expansão difusa e a necessidade de redefinir o papel da abordagem das ciências sociais e humanas (ABRASCO, 2003).

Após adiamentos sucessivos, em função de outros eventos da associação, organizou-se o III Congresso Brasileiro de Ciências Sociais e Humanas em Saúde, nos dias 13 de julho a 18 de julho de 2005 em Florianópolis, presidido por Madel T. Luz, com o tema central "Desafios da fragilidade da vida na sociedade contemporânea". Foi um evento de grande porte e muito maior do que os anteriores, com 1.800 inscritos e 2.032 trabalhos, dos quais 443 foram apresentados oralmente e 1.589 na forma de pôster (ABRASCO 2005, p. 2).

O editorial do Boletim da Abrasco, dedicado ao congresso, destacou sua importância: de um lado, "a necessidade de reflexão articulada no campo das ciências sociais e humanas sobre a saúde e a qualidade de vida das populações”; de outro, a dinamização da área de ciências sociais e humanas em saúde, face a seu crescimento notável (ABRASCO, 2005, p. 16-17). Contudo, segundo pronunciamentos oficiais da associação (ABRASCO, 2005, p. 2), o congresso permitiria o avanço na compreensão da determinação social, econômica e política do processo saúde/doença, configurando um entendimento ainda restrito da contribuição das ciências sociais e humanas à Saúde Coletiva, que não espelha a ampliação das reflexões de sua produção acadêmica, que inclui e ultrapassa aqueles determinantes.

Neste congresso, uma oficina debateu as ciências sociais e humanas no campo da Saúde Coletiva, traçando novas diretrizes para equacionar os problemas prioritários da área, especialmente sobre seu necessário reconhecimento pelas 
agências de fomento e da Capes, e a necessária revisão dos critérios de julgamento e inclusão de sua produção científica, elaborando-se um novo Plano Diretor a ser retomado posteriormente.

Voltaram-se, portanto, os olhares para a conquista de maior legitimidade das CSHS nas instâncias decisórias de ciência e tecnologia, sem o propósito de afetar ou sobrepor a mutidisciplinaridade da Saúde Coletiva. A CCSHS, que durante um certo período foi transitória (CCSHS, 2002) e coordenada por Madel T. Luz até a realização da Oficina de Ciências Sociais e Humanas em Saúde (CCHSS, 2003), recompôs-se a seguir, sob a coordenação de Sílvia Gershman (ENSP) e demais membros: Madel T. Luz (UERJ), Kenneth Camargo Jr. (UERJ), Gilberto Hochman (COC-FIOCRUZ), Everardo Duarte Nunes (UNICAMP), Maria Helena Mendonça (ENSP), Roseni Pinheiro (UERJ), Ilara Hammerli (ENSP), Tânia Fernandes (COCFIOCRUZ), Jussara Calmon e André Martins, derivando do comitê local organizador do I Simpósio Nacional já mencionado, sediado no Rio de Janeiro e reconhecida, oficialmente, no VII Congresso da Abrasco, realizado em Brasília em 2005.

Sílvia Gershman permaneceu na coordenação da comissão, após aquela oficina, até abril de 2006, quando solicitou sua substituição (GERSHMAN, 2007). Somente em julho de 2007, durante o IV Congresso Brasileiro de Ciências Sociais e Humanas em Saúde, XIV Congresso da Associação Internacional de Política de Saúde e X Congresso Latino-americano de Medicina Social, realizado em Salvador de 13 a 18 de julho de 2007, recompôs-se a comissão executiva, sob a coordenação de Kenneth Camargo Jr. (UERJ), ao lado de outros representantes, como Leny Trad (UFBa), Sandra Caponi (UFSC); Rubens Adorno (FSP-USP) e demais membros, cujas indicações estavam em processo ao concluirmos este texto.

\section{A estrutura da comissão}

A denominação e a estrutura da comissão alteraram-se no período analisado. A designação inicial como Comissão de Ciências Sociais (CCS) manteve-se até 2000, alterando-se para Comissão de Ciências Sociais e Humanas em Saúde (CCCS) em um contexto de maior reconhecimento da subárea e de suas disciplinas, integrantes da composição multidisciplinar da Saúde Coletiva, da ampliação de seus objetos, assuntos e metodologias de investigação empregadas. Observam-se contudo, mais recentemente, nos documentos da própria comissão, ambigüidades na sua denominação, ora referida como Comissão de Ciências Sociais e Humanas em 
Saúde, ora como Comissão de Ciências Humanas e Sociais em Saúde, revelando entendimentos institucionais ou grupais específicos de sua denominação.

No início da década de 1990, esforços mais consistentes e permanentes de formatar a organização da comissão, de definir suas atribuições e o sistema de representação e composição, resultaram na formulação de normas informais e na definição das metas para garantir maior identidade a esta subárea de conhecimento, aglutinar os cientistas sociais, promover eventos próprios, diagnosticar e intervir sobre os problemas, visando a seu amadurecimento.

Os critérios de inclusão foram: ter formação em ciências sociais ou, não sendo formado nestas ciências, trabalhar com ensino e pesquisa na área há mais de cinco anos, tendo formação pós-graduada em Saúde Coletiva. Desta forma, resguardava-se a particularidade das ciências sociais neste campo e os perfis de seus intelectuais, sem descartar a possibilidade da participação dos profissionais de saúde atuantes na subárea.

As representações regionais e institucionais deviam ser sempre respeitadas, desde a organização inicial da comissão, comportando de cinco a sete pessoas no máximo, respeitando-se também a disponibilidade e adesão voluntária dos representantes incluídos nos critérios afixados. O coordenador da comissão sempre foi um nome que gozasse do consenso de seus membros e dos cientistas sociais, geralmente convocados e consultados nos eventos específicos (oficinas, reuniões e outras modalidades), realizados durante os Congressos de Saúde Coletiva. O coordenador é o porta-voz da comissão junto à diretoria da Abrasco, que por sua vez indica um dos componentes da diretoria como interlocutor com as diferentes comissões e grupos de trabalho.

A recomposição da comissão far-se-ia por ocasião das mudanças das gestôes das diretorias da associação, preservando-se pelo menos um dos membros da gestão anterior, com a finalidade de manter a continuidade do trabalho, pressupondo-se o acúmulo de experiência desta pessoa, que poderia ou não ter exercido o cargo de coordenador na gestão anterior.

No fim da década de 1990, em decorrência da maior complexidade e amadurecimento da área das ciências sociais e humanas em saúde, da magnitude das tarefas e dos requerimentos de garantir maior representatividade da comunidade científica, novos critérios foram sugeridos, como o de criar uma comissão ampliada, incluindo representantes das várias disciplinas e dos estados, preservando-se os 
critérios regional e institucional. $\mathrm{O}$ modelo de comissão ampliada, gerado na organização do II Congresso de CSHS, realizado em 1999 em São Paulo (ABRASCO/UNIFESP, 2000), orientou o formato da comissão pelo menos durante um certo período de seu funcionamento, esboçando-se também novos debates e propostas a respeito.

Outro formato de estrutura organizacional da CSHS, formulado em 2003, criou uma Comissão Nacional interdisciplinar com integrantes titulados em ciências sociais e humanas, com produção científica respeitável e tradição na área, contemplando-se a representação dos núcleos de pesquisa, além das instituições formadoras de recursos humanos. Ao lado desta estava a comissão executiva (local) e a comissão ampliada, composta de 15 a 18 pessoas, oriundas das diferentes instituiçôes do país, distribuídas regionalmente e reconhecidas na área (ABRASCO, 2003, p. 18-19). Criou-se também um Conselho Consultivo composto de cientistas sociais fundadores, especialistas da área e ex-coordenadores da CCSHS, que careceu da adesão completa dos indicados (ABRASCO, 2003).

$\mathrm{O}$ modelo acima não parece ainda definitivo, exceto quanto à comissão executiva e a comissão ampliada, dando-se ainda discussões sobre a eficácia e efetividade do funcionamento do Conselho Consultivo, estando descartada a existência da Comissão Nacional.

O fato é que se termina esta análise com um debate ainda inconcluso sobre o formato, a estrutura da comissão e o número de seus membros, segundo o acompanhamento das discussões a respeito, cujos impasses merecem ser ultrapassados para a maior efetividade e continuidade de seus trabalhos. Os critérios de inclusão continuam respeitando a diversidade, o caráter "híbrido", imprimido pela multidisciplinaridade à Saúde Coletiva e à própria subárea, além de estarem mantidas as representações institucionais e regionais ou estaduais, que necessariamente devem contemplar todas as regióes do país e não apenas aquelas onde se consolidaram há mais tempo as ciências sociais e humanas em saúde, como a Região Sudeste, cuja densidade institucional e concentração de cientistas sociais da saúde é maior do que nas demais regiōes (ABRASCO, 1995). Desta forma, o maior conflito sobre os critérios em torno das representações regional ou estadual, assim como da ampliação institucional, concentra-se entre os intelectuais pertencentes à Região Sudeste. Esta concentra o maior número de cientistas sociais e instituiçôes, e novos representantes de 
outras regiōes/estados cujas instituições incluíram mais recentemente cientistas sociais estão sendo contemplados.

A polêmica em torno do perfil dos intelectuais, praticantes das ciências sociais em saúde, se reflete nos critérios da composição da comissão, no reconhecimento de sua produção científica e identidade de seus praticantes. De um lado, incluemse na categoria "híbrida" os não-detentores de graduação em ciências sociais e humanas, titulados nos cursos de pós-graduação em Saúde Coletiva ou naquelas ciências, que acumularam grande experiência no ensino e pesquisa na subárea. De outro, estão os autodesignados como "puros", cientistas sociais graduados nas ciências sociais e humanas, portadores de pós-graduação em Saúde Coletiva/ Saúde Pública ou naquelas ciências, concebidos como "verdadeiros detentores do conhecimento", cujas relaçôes acadêmicas no campo científico e na hierarquia de poder estabelecida em torno da autoridade científica empurram os "híbridos" para o estado liminar permanente e nas posições inferiores daquela hierarquia, muitas vezes independentemente da qualidade científica de sua produção - isto é, pela imposição de categorias classificatórias de inferioridade em relação à sua capacitação, em relação aos " puros”.

Dão-se no campo científico, segundo Bourdieu (2007), disputas acirradas, veladas ou não em torno da autoridade científica. Estas parecem se refletir ainda nas discussões em torno dos critérios de inclusão no sistema de representação da comissão, que podem ser mais e menos excludentes, segundo as concepçôes contidas nas diferentes propostas formuladas a respeito.

\section{Os Planos Diretores de CSHS}

Os Planos Diretores, formalmente elaborados, merecem destaque à medida que foram frutos de debates e discussōes entre os pares e momentos de reflexōes importantes sobre as Ciências Sociais na Saúde Coletiva, de identificação de problemas e montagem de estratégias e metas para o seu equacionamento. Todavia, é preciso observar a existência de iniciativas anteriores (NUNES, 2006, p. 189), que, embora não tenham sido designados como planos diretores, pronunciaram sobre problemas da área, traçando algumas metas e estratégias, como as formuladas na primeira versão do Relatório do Grupo de Trabalho em Ciências Sociais e Saúde (ABRASCO, 1990), cujos problemas identificados foram abordados anteriormente, retomando-se, a seguir, as metas e estratégias traçadas na ocasião. 
Nas primeiras estavam

o balanço da incorporação das ciências sociais da área de saúde; análise da constituição da área da Saúde Coletiva, desde a leitura das ciências sociais; estímulo ao fortalecimento da identidade coletiva dos cientistas sociais na área da saúde; legitimação das ciências sociais em relação à corporação das ciências sociais; ordenamento da produção científica; captação e formação de recursos humanos; adequação da formação de docentes e organização didático-pedagógica e dos conteúdos da prática docente em ciências sociais e saúde. Quanto às estratégias, destacam-se a realização de oficinas de trabalho sobre ensino, pesquisa e produção científica; o relacionamento com a Anpocs e o estabelecimento de trabalho para a comissão de ciências sociais e saúde, programa editorial, elaboração de biblioteca básica e organização do Primeiro Encontro Nacional de Ciências Sociais e Saúde (ABRASCO, 1990, p. 2).

O denominado $1^{\circ}$ Plano Diretor das Ciências Sociais em Saúde foi concluído em 1997, a partir de discussōes em três oficinas específicas, realizadas no Rio de Janeiro, 1995 (ABRASCO, 1995); Campinas, 1996 (ABRASCO, 1997); Águas de Lindóia, 1997 (ABRASCO, 1997), com ampla participação dos especialistas da subárea, cujos problemas identificados na ocasião estão listados a seguir, omitindo-se as estratégias para equacioná-los, que constam do documento original (ABRASCO, 1997):

1) diversidade dos processos formativos dos profissionais de saúde e necessidade de adequar os conteúdos ensinados pelas ciências sociais;

2) falta de docentes e pesquisadores com formação específica em ciências sociais;

3) dificuldade de atualizar os docentes e pesquisadores;

4) falta de maior compatibilidade entre as concepções teórico-metodológicas das ciências sociais nos conteúdos ensinados nos cursos de graduação de profissionais de saúde;

5) experiências institucionais diferentes na incorporação dos conteúdos das ciências sociais nos cursos de P. G de Saúde Coletiva/Saúde Pública/Medicina Social;

6) nos cursos de mestrados e doutorados amplia-se a demanda de especialização, coexistindo com a redução de tempo de duração dos mesmos;

7) necessidade de formar pesquisadores e docentes para a área;

8) necessidade de ampliar o quadro de cientistas sociais nas instituições de ensino e pesquisa; 
9) necessidade de permanente reflexão e integração das diferentes disciplinas de ciências sociais no campo da Saúde Coletiva;

10) necessidade de incorporar novos objetos, decorrentes das transformações da sociedade, no quadro epidemiológico e no plano do conhecimento.

Ainda persistem problemas, embora alguns itens tenham sido mais equacionados do que outros, como a redução do tempo de conclusão das teses e dissertaçôes; a integração das diferentes disciplinas das ciências sociais e humanas, assim como, no plano do conhecimento, tanto ampliaram e diversificaram os objetos de conhecimento examinados à luz das ciências sociais e humanas, quanto se deu a incorporação e maior aceitação dos métodos qualitativos na pesquisa em saúde (LUZ, 1997).

Outros itens ainda não foram inteiramente contemplados, como a maior adequação do ensino nos cursos de graduação de formação dos diferentes profissionais de saúde, a ampliação do quadro de cientistas sociais nas instituições, exceto em poucas instituições. São ainda raras as que conseguiram criar, nos seus cursos de pós-graduação em Saúde Coletiva, áreas de concentração em CSHS, dificultando a formação de futuros quadros especializados, embora algumas instituições de ciências sociais e humanas contribuam atualmente, muito mais do que no passado, à formação de cientistas sociais interessados nos assuntos da saúde, sem que a interdisciplinaridade seja posta em prática.

Incorporam-se, mais recentemente, a algumas universidades das regiōes Nordeste e Sul, cientistas sociais à Saúde Coletiva, enquanto outras reduziram seus quadros, com a aposentadoria de antigos professores. As políticas de contratação, no entanto, pouco contemplam a reposição, como na maioria das universidades estaduais paulistas, estando quase ausentes estes profissionais nas instituições das regiōes Centro-Oeste e Norte. Da mesma forma, ainda é restrita a diversificação dos cientistas sociais nas diferentes disciplinas das ciências sociais e humanas, exceto nas instituições maiores ou em outras tradicionais e mais antigas, pertencentes ao campo de Saúde Coletiva/Saúde Pública.

A discussão sobre a atualização do Plano Diretor, através de uma oficina especialmente convocada, antecedeu a realização do Simpósio Nacional de Ciências Sociais e Humanas em Saúde, reconhecendo-se a diversidade de identidades e formações profissionais e o difuso crescimento desta área, propondo-se reunificála e valorizar a formação específica e estimular a qualificação de sua produção e dos veículos de difusão. Propôs-se também a articulação da comissão com outros grupos 
temáticos da Abrasco e a reorganização daquela comissão em uma Comissão Nacional, da ampliada ao lado de uma outra executiva (ABRASCO, 2003, p. 18). Destacou-se o debate não-unânime de valorizar a formação específica na área de ciências sociais e humanas, em detrimento do reconhecimento do perfil diversificado e "híbrido", apresentado como problema a ser equacionado.

Um outro Plano Diretor da área de CSHS (ABRASCO, 2006) foi elaborado para o período de 2005-2006 na oficina de CSHS, ocorrida durante o IV Congresso Brasileiro de Ciências Sociais e Humanas em Saúde, realizado em Florianópolis em 2006, cujas diretrizes e estratégias apontavam para:

1) a necessidade de incentivar o maior desenvolvimento acadêmico e institucional da área em todo território nacional, através da multiplicação de eventos científicos regionais;

2) ampliar os mecanismos de financiamento e de apoio da Abrasco à comissão, assim como o acesso às publicações de CSHS nas revistas de Saúde Coletiva;

3) envidar esforços junto às revistas de ciências sociais e humanas na ampliação de espaço para publicações de artigos da área;

4) fortalecer a subárea nos diferentes comitês de avaliação e reativar o fórum de coordenadores e pesquisadores de ciências sociais e humanas;

5) fortalecer e identificar os veículos de difusão para dar maior visibilidade e qualificação à produção;

6) estimular a chancela da Abrasco às editoras e/ou coleções que acolhem nossa produção;

7) relembrar à Capes a decisão tomada na Saúde Coletiva de usar o Qualis da área de origem para a Saúde Coletiva das revistas fora da área, quando este for superior à avaliação desta última, revendo-se também os casos discordantes;

8) recomendar à Abrasco e ao Fórum de Coordenador o apoio à adequação dos critérios de pontuação junto às agências de fomento e a Capes;

9) fazer interlocução com outras associações de ciências sociais e de ciências humanas para estabelecer critérios de avaliação ética das pesquisas;

10) criar boletins e outras formas eletrônicas de divulgação das atividades da comissão e atualizar o site da Comissão na página da Abrasco.

A centralidade da produção acadêmica e dos critérios para julgá-las, assim como a busca de legitimidade das CSHS junto às agências de fomento, no interior da 
Saúde Coletiva, ainda está por ser feita. Tais estratégias são importantes para a continuidade do amadurecimento e identidade das ciências sociais e humanas, assim como a revisão do ensino nos diferentes níveis, avaliando-se permanentemente seus conteúdos e metodologias, em especial nos cursos de graduação dos profissionais de saúde, os quais as reformas curriculares recentes modificaram. As atividades de ensino, em todos os níveis, foram e continuam sendo um dos pilares da presença das ciências sociais no campo da Saúde Coletiva, medicina e de outras profissões de saúde, não se esquecendo que foi por esta via que elas penetraram no campo da saúde. Não se minimiza também a importância de rever e qualificar a produção acadêmica, atualmente muito mais densa e diversificada que no passado.

\section{Conclusão}

Não há dúvida sobre o grande impulso da CCSHS da Abrasco, desde a década de 1990, cuja nova designação reflete muito bem as presenças, não-exclusivas, da sociologia ou da ciência política como outrora, mas das demais ciências sociais e humanas, como a filosofia, história, antropologia e, mais residualmente, da economia em saúde. Estas ampliaram o espectro de suas contribuições à Saúde Coletiva, recriaram novos objetos, almejando identidade própria e a prática da interdisciplinaridade, constatados nos diferentes pronunciamentos de abertura oficial dos congressos da área.

No contexto político-institucional da Abrasco e das intervençōes das diferentes gestões, a maior ou menor intensidade do trabalho das comissões reflete o maior ou menor apoio às suas atividades, da parte de algumas diretorias e as iniciativas dos membros da comissão, embora não se disponha de um registro completo a respeito. Essas iniciativas, em muitas ocasiōes, transcenderam a promoção de eventos, como a elaboração de planos para a área, embora persista a forte dependência da comissão do apoio financeiro da associação para implementar as atividades, ainda que outras agências a tenham apoiado na promoção dos congressos. Contudo, a implementação de outras atividades da comissão cerceia-se pelo menor acesso aos órgãos executivos da política de saúde, que costumam ser acionados pelas comissões das demais subáreas, à medida que se apresentam mais instrumentais do que as ciências sociais e humanas, às intervenções na política de saúde. Portanto, ainda está pendente a solução do financiamento das atividades da comissão, que necessita 
ser equacionado para melhor desempenho e condições de seu funcionamento e ampliação de suas atividades.

A crescente magnitude dos eventos implementados atesta a importância e reconhecimento das ciências sociais e humanas no âmbito da Saúde Coletiva em alguns aspectos: fornecer visibilidade à sua crescente produção acadêmica; discutir uma agenda própria capaz de diagnosticar, debater e formular soluções para os problemas específicos desta área no ensino, pesquisa e serviços; aglutinar seus profissionais e instituições; fazer interlocução com outras áreas da Saúde Coletiva e entre as próprias ciências sociais e humanas. Tudo isto certamente se soma ao reforço da Saúde Coletiva.

No entanto, é salutar resguardar o caráter amplo e representativo das diferentes regiōes e instituiçôes na comissão, assim como reiterar e relembrar o perfil "híbrido" dos profissionais que convivem ao lado dos que se designam como "puros", por serem formados nas disciplinas das ciências sociais ou das ciências humanas, que, respeitadas as exceçôes, continuam reivindicando identidade própria.

Ecoam querelas desta natureza em torno do debate e propostas formuladas de revisão da estrutura e composição das comissões, sejam os que insistem na preservação das identidades disciplinares, sejam os que circunscrevem os critérios de inclusão na comissão apenas aos graduados em ciências sociais e humanas, embora seja estratégico compor o campo acadêmico com a presença mais incisiva de cientistas sociais.

De toda forma, no período examinado, debateram-se o aperfeiçoamento da estrutura e representatividade da comissão em relação às instituições do campo, às distintas disciplinas de ciências sociais e humanas, ao sistema de representação estaduais e regionais, estimulando-se também a promoção de eventos em alguns estados, nos períodos intersticiais aos congressos da subárea.

O entendimento do papel das ciências sociais na Saúde Coletiva, segundo observado nas atividades implementadas nas diferentes gestôes ou nos pronunciamentos emitidos, não é homogêneo; restam tensões, que ainda evocam perguntas: meros respaldos instrumentais da política de saúde? Circunscrição aos determinantes sociais do processo saúde e doença e à análise e vocalização da política de saúde? Respeito aos objetos próprios, que não descartam a análise, avaliação e formulação da própria política de saúde, ao lado da abordagem complexa da dimensão dos fenômenos de adoecimento, saúde, vida e morte da população? 
Todos esses processos se diferenciam socialmente, comportando formas diversas de enfrentá-los, conduzindo-se sua análise aos diferentes olhares das ciências sociais e humanas, que são diversas e muito presentes na produção acadêmica, consolidada há quase quatro décadas de trabalho de seus intelectuais e instituições.

Finalmente, o amadurecimento das ciências sociais e humanas no campo da Saúde Coletiva ainda requer esforços contínuos de demarcação de sua identidade, como nas estratégias já formuladas de busca de reconhecimento da especificidade de sua produção acadêmica, de conquistas de espaços junto às agências de ciência e tecnologia. Estas, no entanto, sempre contribuíram na composição e legitimidade da Saúde Coletiva, reivindicando agora maior identidade, no seu interior, para sua permanência e continuidade, que se aplicam também ao cotidiano do funcionamento das instituições do campo da Saúde Coletiva, incluindo o necessário aperfeiçoamento, expansão de sua inclusão, geração e incorporação de novos quadros intelectuais adequadamente capacitados.

\section{Referências}

ASSOCIAÇĀO BRASILEIRA DE PÓS-GRADUAÇÃO EM SAÚDE COLETIVA. I Reunião Nacional sobre Ensino e Pesquisa de Ciências Sociais na Saúde Coletiva. In: Ensino da Saúde Pública, Medicina Preventiva e Social no Brasil. Rio de Janeiro, 1983. v. 2, p 147-161.

. Curso de Atualização para docentes e pesquisadores da área de Ciências Sociais em Saúde . Relatório Final. In: Ensino da Saúde Pública, Medicina Preventiva e Social no Brasil. Rio de Janeiro, 1984. v. 3, p. 143-157.

. Comissão de Ciências Sociais e Humanas em Saúde. Programa do seminário de ciências sociais e humanas em saúde: desafios da saúde e da vida. Rio de Janeiro, Fundação Oswaldo Cruz. 2003. 2 p.

. Comissão de Ciências Sociais em Saúde. Relatório da oficina de ciências sociais em saúde. Boletim da Associação Brasileira de Pós Graduação em Saúde Coletiva. Rio de Janeiro, 1995, n. 56, p 5-7,.

Grupo de trabalho de ciências sociais e saúde: relatório. Rio de Janeiro, 1991,7p.

CONGRESSO DE CIÊNCIAS SOCIAIS E HUMANAS EM SAÚDE, 3., 2006, Rio de Janeiro. Rio de Janeiro: Abrasco, 2006.

ENCONTRO BRASILEIRO DE CIÊNCIAS SOCIAIS EM SAÚDE, 1., 1993, Belo Horizonte. Prospecto... Belo Horizonte: Universidade Federal de Minas Gerais, Departamento de Medicina Preventiva e Social, 1993.4p. 
CONGRESSO BRASILEIRO DE CIÊNCIAS SOCIAIS EM SAÚDE, 2., 2000, São Paulo.

Relatório Científico... São Paulo: Abrasco, 2000. 26p.

ASSOCIAÇÃO BRASILEIRA DE PÓS-GRADUAÇÃO EM SAÚDE COLETIVA. Boletim Associação Brasileira de Pós-Graduação em Saúde Coletiva. Rio de Janeiro: 2005. n 94.

. BOLETIM DA ASSOCIAÇÃO BRASILEIRA DE PÓS GRADUAÇÃO EM SAÚDE COLETIVA. Carta de Curitiba. Rio de Janeiro: 1995. v. 13, n. 59. p. 1.

CATÁLOGO BRASILEIRO DE CIENTISTAS SOCIAIS EM SAÚDE. Rio de Janeiro: ABRASCO, $1995.54 \mathrm{p}$.

ASSOCIAÇÃO BRASILEIRA DE PÓS-GRADUAÇÃO EM SAÚDE COLETIVA. Grupo de trabalho de ciências sociais e saúde: relatório. Rio de Janeiro: 1990. 7p.

. Comissão de Ciências Humanas e Sociais em Saúde. Relatório de gestão. Boletim da Abrasco, v.20, n. 89, p. 4, 2003.

. Comissão de Ciências Humanas e Sociais em Saúde. Histórico da comissão transitória.

Rio de Janeiro: 2002.3 p.

. CONGRESSO DE CIÊNCIAS SOCIAIS E HUMANAS EM SAÚDE, 3., 2006, Florianópolis. Documento resultante da oficina... Florianópolis: Comissão de Ciências Sociais e Humanas em Saúde, 2006; CONGRESSO BRASILEIRO DE SAÚDE COLETIVA, 7., 2006, Florianópolis. Boletim especial... Rio de Janeiro: 2003. v. 20, 19 p.

. Comissão de Ciências Humanas e Sociais em Saúde. Relatório de reuniāo com a diretoria da Abrasco. Rio de Janeiro:1994. 4 p. 13 set.

Comissão de Ciências Humanas e Sociais em Saúde. SIMPÓSIO NACIONAL DE CIÊNCIAS HUMANAS E SOCIAIS EM SAÚDE, 1., 2003, [S.I.]. Ata de reunião... [S.I.]: 25 set. 2003.3 p.

OMISSÃO DE CIÊNCIAS HUMANAS E SOCIAIS EM SAÚDE. Relatório. Oficina de Trabalho Ciências Humanas e Sociais em Saúde. Rio de Janeiro: 29 a 30 de julho 2003. 4p.

ASSOCIAÇÃO BRASILEIRA DE PÓS-GRADUAÇÃO EM SAÚDE COLETIVA. Comissão de Ciências Humanas e Sociais em Saúde In: I Plano Diretor das Ciências Sociais em Saúde. Rio de Janeiro: 1997.10p.

. Comissão de Ciências Humanas e Sociais em Saúde. Memória de reunião de reformulação da primeira versão do plano diretor. Águas de Lindóia. 26 ago. 1997. 2p.

. Comissão de Ciências Humanas e Sociais em Saúde. Termo de Referência: plano diretor das ciências sociais e humanas em saúde. Salvador: 2007. 1p.

ALVES, P.C. Ciências sociais em saúde: perfil do congressista. In: Boletim da Associação Brasileira de Saúde Coletiva. [S.I.]: Associação Brasileira de Saúde Coletiva, 1995. v.13. p 5-6. Especial. 
ARCOVERDE, Cláudio. Cronologia da Associação Brasileira de Pós-Graduação em Saúde Coletiva. In: LIMA, Nísia Trindade; SANTANA, José de Paranaguá (Org.). Saúde coletiva como compromisso: a trajetória da Abrasco. Rio de Janeiro: Editora Fiocruz: Abrasco, 2006. p. 215-227.

BELISÁRIO, Soraya Almeida. Associativismo em Saúde Coletiva: um estudo da Associação Brasileira de Pós-Graduação em Saúde Coletiva-Abrasco. 2002. Tese (Doutorado em Saúde Coletiva) Departamento de Medicina Preventiva e Social. Faculdade de Ciências Médicas Universidade Estadual de Campinas, 2002.

. Congressos da Abrasco: a expressão de um espaço construído. In: LIMA, Nísia Trindade; SANTANA, José de Paranaguá (Org.). Saúde coletiva como compromisso: a trajetória da Abrasco. Rio de Janeiro: Editora Fiocruz; Abrasco, 2006. p. 45-73.

BOURDIEU, Pierre. O campo científico. In: ORTIZ, Renato (Org.). Pierre Bourdieu: sociologia. São Paulo: Ática, 2007. p. 122-155.

CAMPOS, F. E. Considerações sobre a residência de medicina preventiva e social na atual conjuntura brasileira. In: . Boletim da Associação Brasileira de Pós-graduação em Saúde Coletiva. Rio de Janeiro: 2000. n. 76, p 3-5.

CANESQUI, Ana Maria (Org). Dilemas e desafios das ciências sociais na saúde coletiva. Rio de Janeiro: Abrasco; São Paulo: Hucitec, 1995. 165p.

. Discurso de Abertura. In: Congresso Brasileiro de Ciências Sociais em Saúde,1., 1995,

Rio de Janeiro. Boletim da Associação Brasileira de Pós-Graduação em Saúde Coletiva. Rio de Janeiro: 1995. v.13, p. 2-3, Especial.

CANESQUI, Ana Maria; TREVISAN, E. A. Trabalhos apresentados nas comunicações coordenadas e posters. In: Congresso Brasileiro de Ciências Sociais em Saúde, 1., 1995, Rio de Janeiro. Rio de Janeiro: Boletim da Associação Brasileira de Pós-Graduação em Saúde Coletiva, 1995. v.13, p. 7. Especial.

Goldenberg, Paulete; Marsiglia, Regina Maria Giffoni; Gomes, Mara Helena de Andréa (Org). O clássico e o novo: tendências, objetos e abordagens em ciências sociais e saúde. Rio de Janeiro: Editora Fiocruz, 2003. 444p. Cohn, Amélia. Comentário da orelha do livro.

FONSECA, Cristina M. O. A história da Abrasco: política, ensino e saúde no Brasil. In: LIMA, Nísia Trindade; SANTANA, José de Paranaguá (Org.). Saúde coletiva como compromisso: a trajetória da Abrasco. Rio de Janeiro: Editora Fiocruz; Abrasco, 2006. p. 21-41.

GERSHMAN, Silva. Complemento do histórico da ciências sociais e humanas em saúde: comunicação oral, oficina de ciências sociais e humanas em saúde. In: CONGRESSO BRASILEIRO DE CIÊNCIAS SOCIAIS E HUMANAS EM SAÚDE, 4., 2007 , Salvador; CONGRESSO LATINO-AMERICANO DE MEDICINA SOCIAL, 10., 2007, Salvador; CONGRESSO DA ASSOCIAÇÃO INTERNACIONAL DE POLÍTICAS DE SAÚDE, 14., 2007, Salvador. 
GODBAUM, Moisés; BARATA, Rita Barradas. O feito por fazer. In: LIMA, Nísia Trindade; SANTANA, José de Paranaguá (Org.). Saúde coletiva como compromisso: a trajetória da Abrasco. Rio de Janeiro: Editora Fiocruz; Abrasco, 2006. p.79-112

GOLDENBERG, Paulete. Discurso de abertura. In: CONGRESSO BRASILEIRO DE SAÚDE COLETIVA, 2., 1999, [S.I.].3p.

GOLDENBERG, Paulete; MARSIGLIA, Regina Giffoni; GOMES, Mara Helena de Andréa (Org.). O clássico e o novo: tendências, objetos e abordagens em ciências sociais e saúde. Rio de Janeiro: Editora Fiocruz, 2003. 441p.

GOMES, Mara Helena de Andréa; GOLDENBERG, Paulete. Interfaces e interlocuções: os congressos de ciências sociais em saúde. Revista Ciência \& Saúde Coletiva, Rio de Janeiro, v. 8, n.1, p. 251-264, 2003.

GOMES, A. F. Desafios às ciências sociais na área da Saúde. In: ENCONTRO BRASILEIRO DE CIÊNCIAS SOCIAIS EM SAÚDE, 1., 1993, Rio de Janeiro. Discurso de abertura... Rio de Janeiro: Abrasco, 1993. p. 23-30.

LIMA, Nísia Trindade. Carta Convocatória do Seminário de Ciências Sociais e Humanas em Saúde, 1., Rio de Janeiro.

LIMA, Nísia Trindade; SANTANA, José Paranaguá de (Org.). Saúde coletiva como compromisso: a trajetória da Abrasco. Rio de Janeiro: Editora Fiocruz, 2006. 230 p.

LUZ, Madel Therezinha. Orelha de livro. In: CANESQUI, Ana Maria (Org.). Dilemas e desafios das ciências sociais na saúde coletiva. Rio de Janeiro: Abrasco; São Paulo: Hucitec, 1995.

. A produção científica de saúde coletiva (1994-1995). Ciência \& Saúde Coletiva. Rio de Janeiro, v. 2 n. 1-2, p. 117-141, 1997.

LUZ, Madel Therezinha; EWBANK, M. T.O. Quem é quem em ciências sociais e saúde. Rio de Janeiro.

MINAYO, Maria Cecília de Souza. Orelha de livro. In: CANESQUI, Ana Maria (Org.). Ciências Sociais e Saúde. São Paulo: Hucitec, 1997.

- Atuação da Abrasco em relação ao ensino de pós-graduação na área da saúde. In: LIMA, N. T; SANTANA, J. P. (Org.). Saúde coletiva como compromisso: a trajetória da Abrasco. Rio de Janeiro: Editora Fiocruz, 2006. p. 117-148.

MINAYO, Maria Cecília de Souza; COIMBRA, C. Apresentação. In: Ciências Sociais e Humanas em Saúde na América Latina. Rio de Janeiro: Editora Fiocruz, 2005. p 12-16.

Noronha, J C. Uma Abrasco atuante e propositiva: um balanço da gestão 2000-2003: Editorial. Boletim da Associação Brasileira de Saúde Coletiva, v.20, n. 89, p. 1, 2003.

NEHMY, R.Q; SOUZA, M.S.L; MENDONÇA, M.C.L. PRODUÇÃO CIENTÍFICA DO ENCONTRO BRASILEIRO DE CIÊNCIAS SOCIAIS EM SAÚDE,1., 1993, Rio de Janeiro. 
Posters... In: ENCONTRO BRASILEIRO DE CIÊNCIAS SOCIAIS EM SAÚDE,1., 1993, Rio de Janeiro. Anais... Rio de Janeiro: Abrasco, 1993. p.11-113.

NUNES, E D. Comissão e Grupos de Trabalho. In: LIMA, N.T; SANTANA, J.P. (Org.). Saúde coletiva como compromisso: a trajetória da Abrasco. Rio de Janeiro: Editora Fiocruz, 2006. p. 187-231.

\section{Notas}

${ }^{1}$ Falhas e omissões nas informações divulgadas neste texto não foram intencionais, mas dificultadas pelo acesso às informaçôes. Agradeço aos que prontamente atenderam às solicitaçôes: Sílvia Gershman, Mara Helena de Andréa Gomes, Paulete Goldenberg, Madel T. Luz e Kenneth Camargo Jr.

${ }^{2}$ Retomando somente as informações da procedência regional dos cientistas sociais, verificou-se que 88\% se concentravam na Região Sudeste, com superioridade do Rio de Janeiro sobre São Paulo e Minas Gerais; 6,3\% estavam no Nordeste, distribuídos em iguais proporções nos estados da Bahia e Rio Grande do Norte; 5,1\% estavam na Região Sul, com maior vantagem do Estado do Rio Grande do Sul sobre Paraná e Santa Catarina, e apenas 0,6\% originaram-se da Regiāo Centro-Oeste (ABRASCO, 1997).

${ }^{3}$ Estudo sobre os 68 resumos dos trabalhos encaminhados para pôsteres no I Encontro (NEHMY et al., 1993, p. 111-112) indica as áreas temáticas que não foram apenas pertinentes às ciências sociais, tais como: Epidemiologia, 16,3\%; Política de saúde, serviços, programas e avaliação, 20,1\%; Saúde e doença, 13,2\%; Programas educativos, 5,7\%; Condição feminina e reprodução, 4,4\%; Ensino e formação de pessoal 10,2\%; Saúde mental, 4,4\%; Profissōes de saúde, 2,9\%; Violência, 2,9\%; Práticas alternativas de cura 5,9\%; outros, 5,9\%.

${ }^{4}$ No levantamento feito entre 186 congressistas, verificou-se predomínio do gênero feminino, sendo que 30,0\% eram formados em Ciências Sociais; 17,5\% em Serviço Social; 14,0\% em Medicina e 13,2\% em Enfermagem e os demais em outras profissões (ALVES, 1995).

${ }^{5}$ Os temas das comunicações e pôsteres apresentados no I Congresso foram: Saúde e doença, 26,7\%; Políticas e serviços de saúde, 19, 2\%; Recursos humanos, 13, 0\%; Saúde mental (doenças, instituições e políticas), 5,45\%; Violência e saúde, 4,45\%; Movimentos sociais e saúde, 2,7\%; Sistemas médicos e terapêuticos, 2,75\%; Teoria e metodologia, 2,0\%; outros, 4, 4\% (CANESQUI; TREVISAN, 1995).

${ }^{6} \mathrm{O}$ perfil dos congressistas do II Congresso, segundo seu relatório final (BARSCO, 2000), foi o seguinte: quanto à procedência, 69,5\% vieram da Região Sudeste, predominando os estados de São Paulo e Rio de Janeiro, nas proporções respectivas de 32,6\% e 30,5\%. Somando o restante dos demais estados, destaca-se o Nordeste, com 16,9\% dos congressistas, seguido de estados sulinos (8,45\%), estados da Região Centro-Oeste (4,75\%) e reduzidas proporções dos oriundos dos estados da Região Norte $(0,85 \%)$. Verifica-se, em relação ao I Congresso, a ampliação dos participantes oriundos da Região Nordeste. Quanto à origem institucional, 87,5\% pertenciam às universidades e aos centros de pesquisa; $8,3 \%$ às instituiçôes prestadoras de serviços e o restante não teve origem identificada. Quanto às áreas de conhecimento, predominaram os cientistas sociais $(34,0 \%)$ e os cientistas biológicos e biomédicos $(33,7 \%)$, verificando-se a presença de estudantes $(5,7 \%)$, comunicadores, publici- 
tários, estatísticos e profissionais de computação em reduzidas proporções, assim como os que se identificaram como docentes e pesquisadores, omitindo sua área de conhecimento (23,9\%).

${ }^{7}$ Sobre os assuntos apresentados no I Encontro de 1993 e nos I e II Congressos de Ciências Sociais em Saúde, segundo os campos disciplinares, Gomes \& Goldenberg (2003) observaram: 1) na antropologia, a permanência da análise dos sistemas tradicionais ou alternativos de cura, os estudos de gênero, representações e práticas sobre saúde-doença (concepçôes das doenças e racionalidades; corpo, risco, urgência; prevenção); cultura e subjetividade e abordagens metodológicas (interacionismo simbólico e fenomenologia); 2) na sociologia e política, a análise da política, seus eventos, descentralização, movimentos sociais; participação social; Estado e cidadania; reforma sanitária; relações público e privado; política e programas (saúde mental; saúde do trabalhador; saúde da mulher/gênero; saúde da família); formas de gestão; eqüidade, cidadania; promoção da saúde, ética e saúde, análises históricas das políticas e reflexões teórico-metodológicas; 3) na educação em saúde estavam os usuários, a educação popular, a formação de recursos humano, tecnologias de ensino, reforma curricular; ensino das ciências sociais; 4) na epidemiologia (1/3 dos trabalhos) havia maior ou menor interlocução com as ciências sociais, discussões teóricometodológica da interdisciplinaridade da epidemiologia com as ciências sociais, estudos sobre reprodução humana e gênero, incluindo a masculinidade e riscos; os perfis da morbi-mortalidade e violência; saúde e trabalho, preocupaçôes com o ambiente e saúde e migrações e doença. 


\section{Abstract}

\section{Health Social and Human Sciences at ABRASCO}

This paper analyzes the Social Science and Human in Health Commission at the Brazilian Collective Health Association and its trajectory, structure, organization and activities implemented from 1981 to 2006, within its administrative context, which gave major support to it, highlighting the different association and commission administrations. Abrasco's documents were used, such as journals, written reports, speeches from former coordinators and specific bibliography, such as reports from former coordinators or members. The paper allows concluding that from the initial difficult to communicate with the Collective Health area, the social sciences legitimated themselves and expanded their subject and disciplines, establishing their identity, which demands new fronts. The Commission organized itself, established informal rules, defining and redefining its representation system and shape. The commission's major activities were: promotion of scientific events; diagnosis and strategies to solve specific problems; accomplishment of goals established by the association and response to its intellectuals' initiatives to set up the role of the social and human sciences in the Collective Health, organizing its professionals and interventions.

> Key words: Abrasco Commission; Social and Human Sciences in health; activities, structure; organization; directory plans. 